\title{
OPTIMASI RASIO MOLAR DAN WAKTU REAKSI PADA PEMBUATAN BIODIESEL DARI MINYAK BIJI MALAPARI (Pongamia Pinnata L.) DENGAN KATALIS ABU SEKAM PADI TERMODIFIKASI LITIUM
}

\author{
Komang Ayu Tri Lestari ${ }^{*}$ I Nengah Simpen dan Sri Rahayu Santi \\ Jurusan Kimia, Fakultas Matematika dan Ilmu Pengetahuan Alam, Universitas Udayana, Bali- \\ Indonesia \\ *E-mail : ayutrilestarikm@gmail.com
}

\begin{abstract}
ABSTRAK: Minyak biji malapari merupakan bahan baku yang potensial untuk produksi biodiesel. Penelitian ini mempelajari optimasi rasio molar minyak:metanol dan waktu reaksi pada produksi biodiesel menggunakan minyak biji malapari dalam reaksi transesterifikasi dengan katalis abu sekam padi termodifikasi litium (Li). Variasi parameter yang digunakan untuk mendapatkan kondisi optimum yaitu rasio molar minyak:metanol dengan perbandingan 1:6; 1:9 dan 1:12 dengan waktu reaksi 150, 180, dan 210 menit menggunakan massa katalis $3 \%$ pada suhu reaksi $60-65^{\circ} \mathrm{C}$. Kebasaan permukaan, situs aktif, dan morfologi permukaan katalis heterogen sebelum transesterifikasi $\left(\mathrm{Li}-\mathrm{ASP}_{1}\right)$ dan setelah transesterifikasi $\left(\mathrm{Li}-\mathrm{ASP}_{2}\right)$ dikarakterisasi. Hasil penelitian menunjukkan bahwa yield biodiesel tertinggi yaitu 88,37\% diperoleh pada rasio molar minyak:metanol sebesar 1:9 dengan waktu reaksi 150 menit. Biodiesel tersebut telah memenuhi Standar Nasional Indonesia (SNI) 04-7182-2006 dengan massa jenis, viskositas, bilangan asam, bilangan iod, kadar air, dan bilangan setana berturutturut sebesar $885,3 \mathrm{~kg} / \mathrm{m}^{3} ; 5,75 \mathrm{cSt} ; 0,27 \mathrm{mgKOH} / \mathrm{g} ; 45,89 \mathrm{~g} \mathrm{I} / 100 \mathrm{~g}$ biodiesel, $0,01 \%$ dan 65,13. Nilai kebasaan permukaan katalis $\mathrm{Li}_{-} \mathrm{ASP}_{1}$ yaitu 20,0984 $\pm 0 \mathrm{mmol} \cdot \mathrm{g}^{-1}$ lebih besar dibandingkan dengan nilai kebasaan katalis Li-ASP 2 sebesar 10,6516 $\pm 0 \mathrm{mmol}^{-1} \mathrm{~g}^{-1}$, situs aktif katalis $\mathrm{Li}_{-} \mathrm{ASP}_{1}$ sebesar $1,2103 \times 10^{22}$ atom $\mathrm{g}^{-1}$ memiliki nilai yang lebih tinggi dibandingkan katalis Li-ASP 2 sebesar 0,6414 x $10^{22}$ atom g ${ }^{-1}$. Morfologi permukaan katalis Li-ASP 1 dan Li$\mathrm{ASP}_{2}$ menunjukkan bahwa distribusi pori terlihat kurang homogen dengan bentuk partikel yang terdistribusi secara tidak merata.
\end{abstract}

Kata kunci : minyak biji malapari, transesterifikasi, biodiesel, abu sekam padi termodifikasi litium

ABSTRACT: Pongamia oil is a potential oil for producing biodiesel. The aim of this research is to find the optimum conditions of transesterification rection of pongamia oil using lithium-modified rice husk ashes (Li-ASP) in producing biodiesel. The molar ratio of oil:methanol (1:6;1:9; and 1:12) and the reaction time (150; 180; and 210 minutes) were used as parameters using $3 \%(\mathrm{w} / \mathrm{w})$ of the catalyst at reaction temperature of $60-65^{\circ} \mathrm{C}$. Moreover, the heterogeneous catalysts before the transesterification ( $\left.\mathrm{Li}-\mathrm{ASP}_{1}\right)$ and after transesterification $\left(\mathrm{Li}-\mathrm{ASP}_{2}\right)$ were characterized by their surface alkalinities, active sites and surface morphologies. The results showed that the highest biodiesel yield of $88,37 \%$ was gained at molar ratio of oil:methanol of $1: 9$ and 150 minutes of the reaction time. The obtained biodiesel fulfills the Indonesian Nasional Standards (SNI 04-7182-2006) with values 
of density, viscosity, acid number, iod number, water content, and cetane number $885.3 \mathrm{~kg} /$ $\mathrm{m}^{3} ; 5.75 \mathrm{cSt} ; 0,27 \mathrm{mgKOH} / \mathrm{g} ; 45.89 \mathrm{~g} \mathrm{I} / 100 \mathrm{~g}$ biodiesel; $0.01 \%$; and 65.13 , respectively. The surface alkalinity of $\mathrm{Li}_{-\mathrm{ASP}_{1}}$ of $20,0984 \pm 0 \mathrm{mmol}^{-1} \mathrm{~g}^{-1}$ wich is higher than the one of Li-

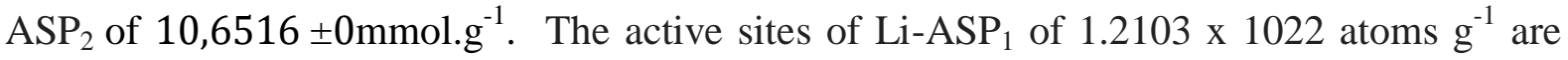
higher than the ones of $\mathrm{Li}_{-\mathrm{ASP}_{2}}$ catalyst of $0.6414 \times 1022$ atoms $\mathrm{g}^{-1}$. The surface morphologies of both Li-ASP1 and Li-ASP 2 indicate that non-homogenous pore distribution showing the unevenly distributed particles.

Keywords : pongamia oil, transesterification, biodiesel, lithium-modified rice husk ashes.

\section{PENDAHULUAN}

Cadangan minyak bumi yang menipis mengakibatkan kuantitas minyak bumi yang semakin berkurang, sehingga diperlukan energi alternatif sebagai pengganti bahan bakar minyak bumi. Biodiesel adalah salah satu energia lternatif yang dapat diperbaharui, rendah emisi, dan biodegradable. Biodiesel dapat diproduksi dengan proses transesterifikasi menggunakan minyak nabati atau lemak hewani dengan alcohol rantai pendek [1]. Pada penelitian ini minyak biji malapari (Pongamiapinnatta L.) sebagai bahan baku dalam pembuatan biodiesel. Minyak biji malapari merupakan minyak non-pangan yang sangat potensial sebagai bahan baku biodiesel karena tidak berkompetisi dengan ketahanan pangan lainnya.

Umumnya, produksi biodiesel menggunakan katalis homogen, karena mengkonversi biodiesel relatif lebih banyak. Katalis homogen merupakan katalis yang memiliki fasa yang sama dengan reaktan dan produknya [2]. Hal ini mengakibatkan pemisahan produk dan katalis yang lebih rumit, dan pencucian produk akhir juga berdampak kurang ramah lingkungan serta kurang ekonomis. Kelemahan-kelemahan tersebut dapat diatasi dengan penggunaan katalis heterogen. Katalis heterogen lebih mudah dipisahkan dari produknya karena memiliki fasa yang berbeda[3], sehingga dapat digunakan untuk proses berkelanjutan.

Abu sekam padi merupakan material padat yang dianggap limbah karena ketersediaanya yang melimpah. Abu sekam padi dapat digunakan sebagai penyangga katalis karena memiliki luas permukaan yang tinggi dan kandungan silika $\left(\mathrm{SiO}_{2}\right)$ yang tinggi, yaitu $87-99 \%$ [4]. Senyawaan silika tidak menunjukkan aktivitas katalitik dalam transesterifikasi trigliserida. Modifikasi abu sekam padi dengan litium diketahui dapat menyediakan situs aktif basa yang mampu mengkatalisis reaksi transesterifikasi dalam pembuatan biodiesel [5] dengan menghasilkan kebasaan permukaan 21,8242 mmol.g ${ }^{-1}$.

$$
\text { Rasio molar minyak:metanol }
$$
merupakan parameter yang mempengaruhi dalam reaksi transesterifikasi [6]. Transesterifikasi merupakan tahap yang paling menentukan dalam proses reaksi minyak (trigliserida) menjadi metil ester (biodiesel). Penambahan metanol berlebih akan menggeser kesetimbangan ke arah produk (kanan). Metanol merupakan alkohol yang sering digunakan dalam proses reaksi transesterifikasi (matanolisis) karena ditinjau dari harga lebih ekonomis, memiliki rantai pendek sehingga reaktivitasnya lebih tinggi dan tidak 
mengakibatkan jelaga pada mesin [7]. Waktu reaksi, selain rasio molar juga mempengaruhi konsentrasi (yield) metil ester. Semakin lama waktu reaksi maka konsentrasi produk yang dihasilkan juga akan meningkat. Keadaan ini membuat molekul-molekul reaktan bertumbukan satu sama lain, tetapi setelah kesetimbangan tercapai tambahan waktu reaksi tidak mempengaruhi hasil reaksi (yield)[8].

\section{PERCOBAAN}

\section{Bahan dan Alat}

Bahan-bahan yang digunakan dalam penelitian ini yakni minyak biji malapari, sekam padi, $\mathrm{Li}_{2} \mathrm{CO}_{3}$ pro-analysis (Sigma Aldrich), spiritus, metanol 98\%, aquades, $\mathrm{NaOH}$ pro-analysis, $\mathrm{HCl} 37 \%$, asam oksalat $1 \mathrm{M}$, kloroform, $\mathrm{KOH}$, etanol 96\%, indikator amilum $1 \%, \quad \mathrm{Na}_{2} \mathrm{~S}_{2} \mathrm{O}_{3}, \mathrm{KI}$, $\mathrm{NaHCO}_{3}, \quad \mathrm{~K}_{2} \mathrm{Cr}_{2} \mathrm{O}_{7}$, asam asetat glasial, aseton $\mathrm{I}_{2}, \mathrm{Br}_{2}$, indikator Phenolphtalein (PP), dan pelet $\mathrm{KBr}$.

Alat yang digunakan dalam penelitian ini antara lain: Gas Chromatography-Mass Spectrometer (GC-MS), labu leher dua, statif dan klem, magnetic stirrer dan hotplate, furnace, piknometer, viskometer, termometer, neraca analitik, ayakan, oven, beriuk, corong pisah, cawan porselen, desikator, dan destilator.

\section{Preparasi Abu Sekam Padi}

Sekam padi yang diperoleh dicuci terlebih dahulu dengan akuades, kemudian dijemur dibawah sinar matahari hingga kering lalu dibakarsampai menghasilkan arang sekam padi yang warnanya hitam. Setelah itu dicuci menggunakan $\mathrm{HCl} 0,1 \mathrm{M}$ untuk menghilangkan mineral dan logam renik ( $\mathrm{Al}, \mathrm{Ca}, \mathrm{K}, \mathrm{Mg}, \mathrm{Mn}$, dan $\mathrm{Na}$ ) yang masih terdapat didalamnya lalu dinetralkan dengan akuades kemudian dikeringkan dalam oven pada temperatur $105^{\circ} \mathrm{C}$ selama 2 jam. Arang sekam padi yang telah bersih dan kering diabukan dalam tanur pada temperatur $700^{\circ} \mathrm{C}$ selama 4 jam. $\mathrm{Abu}$ sekam padi kemudian diayak dengan ayakan berukuran $106 \mu \mathrm{m}-250 \mu \mathrm{m}$ [9]. Abu sekam padi yang diperoleh selanjutnya ditempatkan dalam desikator danditandai sebagai ASP.

\section{Modifikasi Abu Sekam Padi oleh Litium}

Dilakukan pembuatan ASP yang termodifikasi litium dengan temperatur kalsinasi $700^{\circ} \mathrm{C} \quad\left(\mathrm{Li}-\mathrm{ASP}_{700}\right)$. Modifikasi dilakukan menggunakan metode keramik (solid state reaction). Setiap $1 \mathrm{~g}$ ASP dicampurkan dengan 1,23 $\mathrm{g} \mathrm{Li}_{2} \mathrm{CO}_{3}$ pada cawan porselin kemudian didehidrasi pada temperatur $200^{\circ} \mathrm{C}$ selama 30 menit selanjutnya dikalsinasi selama 4 jam pada temperatur $700^{\circ} \mathrm{C}$.

\section{Optimasi Rasio Molar dan Waktu Reaksi pada Pembuatan Biodiesel}

Pertama-tama, 3\% berat katalis terhadap minyak dicampurkan ke dalam metanol dengan variasi rasio molar minyak:metanol (1:6,1:9 dan 1:12) sambil diaduk selama 20 menit. Setelah campuran katalis-metanol disiapkan, secara perlahan campuran ditambahkan ke minyak biji malapari (yang telah dihilangkan kandungan airnya). Reaksi dilakukan pada rentang temperatur $60-65^{\circ} \mathrm{C}$ selama variasi waktu reaksi (90, 120, dan 150 menit) dengan pengadukan konstan. Pemanasan dihentikan setelah reaksi selesai dan hasil reaksi dibiarkan mendingin untuk kemudian ditimbang beratnya sebelum dipindahkan ke dalam corong pisah.

Produk yang dihasilkan dibiarkan dalam corong pisah selama 12 jam sampai terbentuk 2 lapisan. Lapisan bagian atas 
merupakan lapisan biodiesel dan lapisan bagian bawah merupakan lapisan gliserol dan katalis. Lapisan biodiesel dipisahkan dari lapisan gliserol dan katalis kemudian disaring hingga diperoleh hasil yang jernih, selanjutnya didestilasi pada temperatur $65^{\circ} \mathrm{C}$ untuk menghilangkan sisa metanol. Biodiesel yang dihasilkan kemudian ditimbang dan dihitung yield-nya dengan rumus :

$$
\text { Yield }=\frac{\text { massa biodiesel }}{\text { massa hasil transesterifikasi }} \times 100 \%
$$

Produk biodiesel kemudian diuji kandungan metil esternya dengan GC-MS untuk memastikan keberhasilan reaksi transesterifikasi pembentukan biodiesel.

\section{Karakterisasi Biodiesel}

Untuk karakteristik biodiesel parameter yang dianalisis adalah densitas menggunakan piknometer, viskositas menggunakan viskometer Ostwald, kadar FFA dan bilangan asam serta bilangan penyabunan secara kuantitatif dengan titrasi, bilangan iod menggunakan metode Hanus, bilangan setana dan kadar air.

\section{Karakterisasi Katalis $\mathbf{L i}-\mathrm{ASP}_{1}$ dan $\mathbf{L i}$ -} $\mathbf{A S P}_{2}$

Untuk karakteristik katalis sebelum (Li$\left.\mathrm{ASP}_{1}\right)$ dan setelah $\left(\mathrm{Li}-\mathrm{ASP}_{2}\right)$ transesterifi- kasi yang dikarakterisasi adalah keasaman dan kebasaan permukaan katalis dengan titrasi asam-basa, gugus fungsi menggunakan FTIR (Fourier Transform Infrared), dan morfologi permukaan menggunakan SEM (Scanning Electron Microscope).

\section{HASIL dan PEMBAHASAN}

\section{Optimasi Rasio Molar dan Waktu Reaksi terhadap Yield Biodiesel}

Rasio molar alkohol terhadap trigliserida merupakan salah satu faktor yang mempengaruhi yield biodisesel. Rasio molar secara stokiometri untuk reaksi transesterifikasi membutuhkan tiga mol alkohol dan satu mol trigliserida untuk menghasilkan tiga mol metil ester dan satu mol gliserol. Alkohol yang berlebih, menyebabkan kesetimbangan reaksi transesterifikasi akan berjalan ke arah produk (kanan)[10].

Selain rasio molar, parameter yang mempengaruhi yield biodiesel adalah waktu reaksi. Waktu reaksi yang semakin lama dapat menghasilkan yield yang besar karena keadaan ini akan memberikan kesempatan terhadap molekul-molekul reaktan untuk bertumbukan satu sama lain.

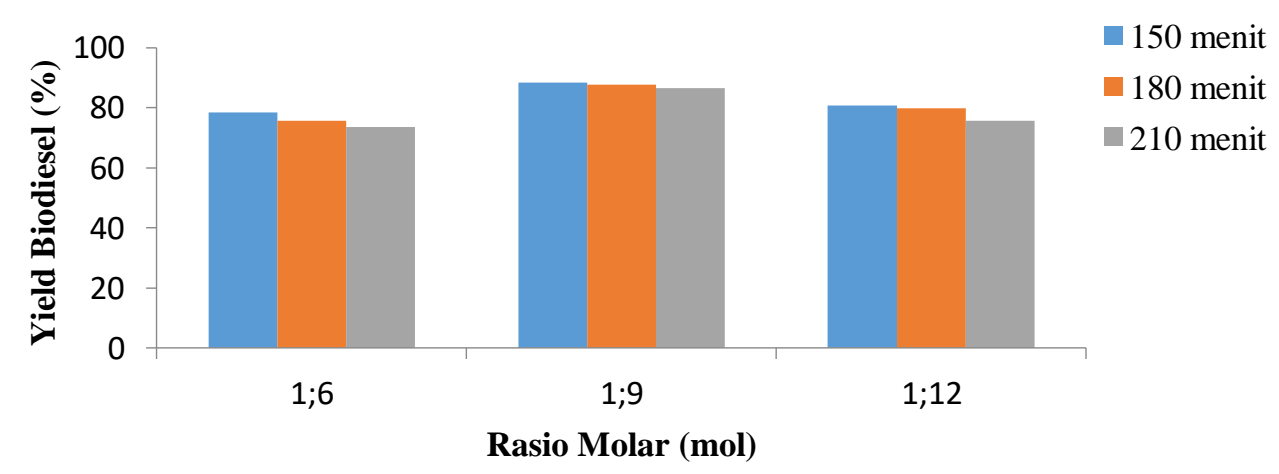

Gambar 1. Grafik pengaruh rasio molar minyak:metanol dan waktu reaksi terhadap yield biodiesel 
Tabel 1. Kromatogram Biodiesel dari Minyak Biji Malapari

\begin{tabular}{ccc}
\hline $\begin{array}{c}\text { Waktu Retensi } \\
(\text { menit})\end{array}$ & Luas Spektra $(\%)$ & Identifikasi Senyawa \\
\hline 15,230 & 5,11 & Metil miristat \\
16,326 & 0,93 & Metil palmitat \\
17,116 & 0,65 & Metil -7- heksadekenoat \\
17,165 & 2,91 & Metil palmitoleinat \\
17,370 & 28,26 & Metil palmitat \\
18,146 & 1,21 & Metil cis-10-heptadekenoat \\
18,375 & 2,82 & Metil heptadekanoat \\
19,044 & 45,20 & Metil linoleat \\
19,234 & 12,91 & Metil oleat \\
\hline
\end{tabular}

Gambar 1 menunjukkan bahwa rasio minyak:metanol yang optimum adalah 1:9 pada waktu reaksi 150 menit dengan yield $88,34 \%$. Reaksi transesterifikasi merupakan reaksi kesetimbangan, sehingga jika kesetimbangan telah tercapai penambahan mol metanol maupun waktu reaksi tidak mempengaruhi yield metil ester. Penggunaan metanol dalam jumlah kecil lebih menguntungkan dari pada penggunaan metanol dalam jumlah besar. Penggunaan perbandingan mol yang lebih tinggi (1:12) antara minyak:metanol menyebabkan proses pemisahan gliserol semakin sulit, karena terjadi peningkatan kelarutan gliserol di dalam metanol yang digunakan.

\section{Analisis dan Karakterisasi Biodiesel}

Analisis biodiesel hasil
transesterifikasi dilakukan menggunakan Chromatograph-Mass Spectrometry (GCMS) untuk mengetahui kandungan metil ester pada biodiesel dari minyak biji malapari sedangkan karakteristik biodiesel yang diuji untuk mengetahui kualitas biodiesel. Karakteristik yang diuji adalahmassa jenis, viskositas, kadar air, bilangan asam, bilangan iod dan bilangan setana. Biodiesel yang dianalisis adalah biodiesel yang dihasilkan pada kondisi optimum yaitu pada rasio molar minyak:metanol 1:9 selama 150 menit

Pemisahan senyawa dengan Gas Chromatograph menunjukkan 9 puncak kromatogram. Puncak tertinggi yaitu terdapat pada waktu retensi 19,044 menit. Analisis dilakukan terhadap puncakpuncak utama dari kromatogram dengan Mass Spectrometry. Berdasarkan pada Tabel 1 diamati bahwa kandungan metil ester tertinggi dalam biodiesel pada kondisi optimum adalah metil linoleat. Senyawa dengan puncak tertinggi menghasilkan waktu retensi 19,044 menit yang berarti senyawa tersebut terpisah pada waktu 19,044 menit dengan luas spektra 45,20\%. Untuk pengujian karakteristik biodiesel dilakukan perbandingan antara biodiesel yang dihasilkan dengan karakteristik biodiesel yang telah ditetapkan dalam SNI-04-71822006 seperti tersaji pada Tabel 2.

Berdasarkan data yang terangkum dalam Tabel 2 menunjukkan bahwa biodiesel pada kondisi optimum telah 
memenuhi standar biodiesel SNI 04-71822006. Karakteristik biodiesel yang diuji berada dalam rentang standar yang ditetapkan. Massa jenis menggambarkan adanya zat-zat pengotor pada biodiesel, misalnya sisa katalis dan metanol, gliserol, sabun, air dan asam-asam lemak yang tidak terkonversi menjadi metil ester [11]. Data dalam penelitian ini menunjukkan nilai massa jenis sebesar $885,3 \mathrm{~kg} / \mathrm{m}^{3}$ yang telah memenuhi standar SNI 04-71822006. Viskositas mengindikasikan kecepatan alir bahan bakar melalui injektor yang mempengaruhi derajat atomisasi bahan bakar dalam ruang bakar. Semakin tinggi viskositas atau semakin kental bahan bakar maka akan menyulitkan aliran, pemompaan dan penyalaan [12]. Viskositas kinematik dengan nilai 5,75 cSt dapat menunjukkan kekentalan biodiesel yang tinggi karena terdapatnya banyak senyawa. Hasil ini didukung oleh data GC-MS (Tabel 1) bahwa biodiesel pada kondisi optimum terdapat 9 senyawa. Bilangan asam pada biodiesel kondisi optimum telah memenuhi standar SNI 04-7182-2006 yaitu 0,27 $\mathrm{MgKOH} /$ gbiodiesel. Angka iodin menunjukkan banyaknya ikatan rangkap dua pada asam lemak penyusun biodiesel. Jumlah ikatan rangkap yang bereaksi dengan iodin menghasilkan senyawa yang jenuh [13], sedangkan asam lemak tidak jenuh pada biodiesel meningkatkan performan mesin pada suhu rendah. Hasil yang diperoleh adalah bilangan iodin sebesar 45,89 $\mathrm{gI}_{2} / 100 \mathrm{~g}$ biodiesel yang telah memenuhi standar SNI 04-7182-2006. Kadar air maksimal dalam biodiesel menurut SNI 2006 adalah 0,05\%. Hasil pengujian kandungan air pada Biodiesel dari minyak biji malapari sebesar 0,01\%. Ini menunjukkan biodiesel dari minyak biji malapari telah memenuhi standar. Bilangan setana biodiesel pada kondisi optimum sebesar 65,13 telah memenuhi standar SNI 04-7182-2006. Bilangan setana adalah \% volume n-setana di dalam bahan bakar yang berupa campuran $\alpha$-metil naftalena $\left(\alpha-\mathrm{CH}_{3}-\mathrm{C}_{10} \mathrm{H}_{7}\right)$ dan n-setana $\left(\mathrm{n}-16 \mathrm{H}_{37}\right)$ [14].

Tabel 2. Perbandingan Karakteristik Biodiesel Hasil Transesterifikasi Minyak Biji Malapari dengan Biodiesel SNI 04-7182-2006 [15]

\begin{tabular}{cccc}
\hline Parameter & Satuan & Biodiesel & $\begin{array}{c}\text { Standar } \\
\text { Biodiesel } \\
\text { (SNI) }\end{array}$ \\
\hline $\begin{array}{c}\text { Massa Jenis } \\
\text { pada } 40^{\circ} \mathrm{C}\end{array}$ & $\mathrm{kg} / \mathrm{m}^{3}$ & 885,3 & $850-890$ \\
$\begin{array}{c}\text { Viskositas } \\
\text { Kinematis } \\
\text { pada } 40^{\circ} \mathrm{C}\end{array}$ & $\mathrm{mm}^{2} / \mathrm{s}(\mathrm{cSt})$ & 5,7532 & $2,3-6,0$ \\
$\begin{array}{c}\text { Air dan } \\
\text { Sediman }\end{array}$ & $\%$ vol & 0,01 & Maks. 0,05 \\
Angka Asam & $\begin{array}{c}\text { mg KOH/g } \\
\text { biodiesel }\end{array}$ & 0,27 & Maks. 0,8 \\
Angka & & & \\
Setana & - & 65,13 & Maks. 115 \\
Angka & & & \\
Iodium & (g.I $/ 100 \mathrm{~g})$ & 45,8884 & Maks. 115
\end{tabular}

Tabel 3. Nilai Kebasaan Permukaan dan Jumlah Situs Aktif Katalis

\begin{tabular}{ccc}
\hline $\begin{array}{c}\text { Jenis } \\
\text { Sampel }\end{array}$ & $\begin{array}{c}\text { Kebasaan } \\
\text { Permukaan } \\
\left(\mathbf{m m o l ~ g}^{-1}\right)\end{array}$ & $\begin{array}{c}\text { Jumlah Situs } \\
\text { Aktif Basa } \\
\left(\text { atom g }^{-1}\right)\end{array}$ \\
\hline Li-ASP $_{1}$ & $20,0984 \pm 0$ & $1,2103 \times 10^{22}$ \\
Li-ASP $_{2}$ & $10,6516 \pm 0$ & $0,6414 \times 10^{22}$ \\
\hline
\end{tabular}




\section{Karakterisasi Katalis Kebasaan dan Keasaman Permukaan Katalis}

Karakteristik kebasaan dan keasaman permukaan katalis dilakukan dengan titrasi asam-basa. Hasil karakterisasi kebasaan permukaan abu sekam padi termodifikasi litium sebelum transesterifikasi ( $\mathrm{Li}-\mathrm{ASP}_{1}$ ) dan setelah transesterifikasi ( $\left.\mathrm{Li}-\mathrm{ASP}_{2}\right)$ memperlihatkan karakteristik basa (situs aktif basa) (tersaji pada Tabel 3). Data tersebut menunjukkan terjadinya penurunan kebasaan permukaan yang berpengaruh terhadap nilai situs aktif basa. Situs aktif basa $\mathrm{Li}^{-\mathrm{ASP}_{1}}$ yang semula sebesar $1,2103 \times 10^{22}$ atom $\mathrm{g}^{-1}$ setelah digunakan sebagai katalis dalam proses transesterifikasi $\left(\mathrm{Li}-\mathrm{ASP}_{2}\right)$ jumlah situs aktif basa menjadi $0,6414 \times 10^{22}$ atom $\mathrm{g}^{-1}$. Penurunan jumlah situs aktif dipengaruhi oleh peracunan katalis (poisoning) dan adanya pengotor (fouling) seperti air, sabun, asam lemak, dan gliserol [16]. Pengotor pengotor hasil reaksi transesterifikasi akan teradsorpsi secara fisik maupun kimia pada permukaan katalis sehingga pori-pori akan tertutup dan situs aktif akan terbungkus oleh pengotor.

\section{Morfologi Permukaan Katalis}

Karakteristik morfologi permukaan katalis $\mathrm{Li}_{-\mathrm{ASP}_{1}}$ danLi-ASP 2 dengan pembesaran 5000 kali ditunjukan pada Gambar 2. Morfologi permukaan katalis $\mathrm{Li}^{-\mathrm{ASP}_{1} \text { danLi-ASP }} \mathrm{A}_{2}$ menunjukkan bahwa distribusi pori terlihat kurang homogen dengan bentuk partikel yang terdistribusi secara tidak merata. Katalis setelah transesterifikasi (Li-ASP ${ }_{2}$ menunjukkan bahwa pori-pori pada katalis telah tertutupi oleh pengotor-pengotor (foulant) yang merupakan hasil samping dari reaksi transesterifikasi pada pembuatan biodiesel dibandingkan dengan katalis $\mathrm{Li}^{-\mathrm{ASP}_{1}}$ yang terlihat lebih besar. Namun, pori-pori pada katalis $\mathrm{Li}^{-\mathrm{ASP}_{2}}$ masih terlihat, sehingga dimungkinkan masih bisa digunakan (diregenerasi).
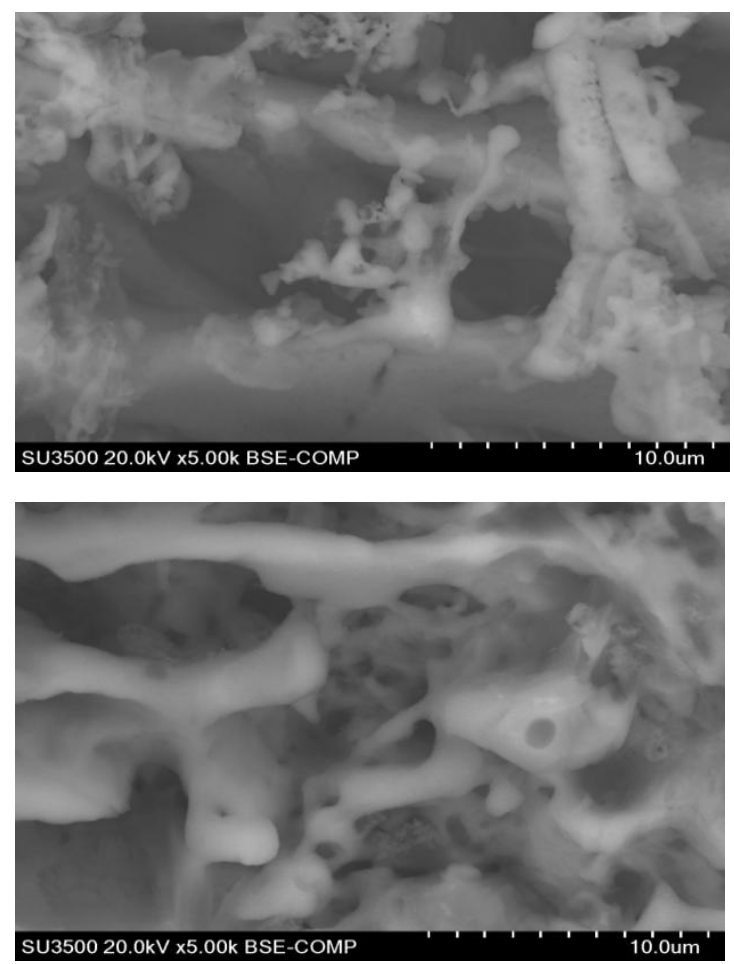

Gambar 2. Morfologi permukaan katalis Li$\mathrm{ASP}_{1}$ (atas) dan Li-ASP 2 (bawah) dengan pembesaran 5000 kali.

\section{KESIMPULAN}

Berdasarkan hasil penelitian yang telah dilakukan, maka dapat disimpulkan bahwa rasio molar minyak:metanol dan waktu reaksi optimum dalam proses produksi biodiesel hasil transesterifikasi minyak biji malapari (Pongamia pinnata L.) pada rasio molar 1:9 dan waktu reaksi 150 menit dengan yield $88,37 \%$. Biodiesel pada kondisi optimum telah memenuhi SNI 047182-2006 yang memiliki massa jenis, viskositas, bilangan asam, bilangan iod, kadar air, dan bilangan setana berturut-turut sebesar $885,3 \mathrm{~kg} / \mathrm{m}^{3} ; 5,75 \mathrm{cSt} ; 0,27 \mathrm{mgKOH} /$ g; 45,89 gIod/100g biodiesel; 0,01\%; dan 65,13 . 


\section{UCAPAN TERIMAKASIH}

Penulis mengucapkan terimakasih kepada ibu Dr. Dra. Ni Made Suaniti, M.Si. dan ibu Oka Ratnayani, S.Si., M.Si. serta kepada pihak-pihak yang telah membantu dalam penyelesaian penelitian ini.

\section{DAFTAR PUSTAKA}

[1] Knothe, G., 2002, Current perspectives on biodiesel,Information,13 (12) : 900903

[2] Sharma, Y. C., Singh, B., and Korstad, J., 2011, Latest Developments on Application of Heterogenous Basic Catalysts for an Efficient and Eco Friendly Synthesis of Biodiesel,A review, Fuel,90 (16) : 1309-1324

[3] Helwani, Z., Othman, M. R., Aziz, N., Kim, J., dan Fernando, W. J. N., 2009, Solid heterogeneous catalysts for transesterification of triglycerides with methanol,A review, Applied Catalysis AGeneral,363 (1-2) : 1-10

[4] Della, V.P., Kuhn, I., Hotza, D., 2002, Rice husk ash as an alternate source for active silica production,Materials Letters,57 (4): 818-821

[5] Dwitama, M. I., Nazib, M., Sitepu O. C., Suandi, D. A. P. dan Simpen, I N.,2016,Konversi Minyak Biji Malapari (Pongamia Pinnata L.) menjadi Biodiesel melalui Pemanfaatan Katalis Heterogen Abu Sekam Padi Termodifikasi Li,Jurnal Kimia, 10 (2) : 236-244

[6] Freedman, B., Pryde, E. H. dan Mounts, T. L., 1984. Variable Affecting the Yield of Fatty Ester from Transesterified Vegetable Oil, America Oil Chemists Society, 61(10): 1638-1643
[7] Fangrui, M., and Hanna, M. A., 1999. Biodiesel Production, $A$ Review, Bioresource Technology, 70 (1) :1-15

[8] Affandi, R. D. N., Aruan, T. R., Taslim, Iriany., 2013. Produksi Biodiesel dari Lemak Sapi dengan Proses Transesterifikasi dengan Katalis Basa $\mathrm{NaOH}$, Jurnal Teknik Kimia Universitas Sumatera Utara, 2(1) : 1-6

[9] Hardjono, 1987. Teknologi Minyak Bumi, Universitas Gajah Mada, Yogyakarta

[10] Liu, X., Piao, X., Wang, Y., Zhu, S., 2008. Transesterification with Heterogenous Catalyst in Production of Biodiesel, Energy Fuels, 22(5): 1313-1317

[11] Setyawati, E. dan Edwar, F., 2012. Teknologi Pengolahan Biodiesel dari Minyak Goreng Bekas dengan Teknik Mikrofiltrasi dan Transesterifikasi sebagai Alternatif Bahan Bakar Mesin Diesel, Jurnal Riset Industri, 6(2) : 117-127

[12] Canaki, M. dan Gerpen, J. V., 2007. Biodiesel from oils and fats with high free fatty acid,Trans America Society of Automotive Engine, 44 (11): 1429-1436

[13] Sudarmadji, S., Haryono, B., dan Suhardi., 1984. Analisa Bahan Makanan dan Pertanian, Liberty. Yogyakarta

[14] Silva, A. O. S., Souza, M. J. B., Aquino, J., Fernandez, V. J. Jr, and Araujo, A. S., 2004. Coke Removal of The HZSM-12 Zeolite With Different Silica/Alumina Ratio (Kinetic Study). Journal of the Thermal Analysis and Calorimetry 75: 482-532

[15] Standar Nasional Indonesia (SNI), 2006. Standar Biodiesel Nasional, SNI Nomor: (SNI 04-7182-2006) 
[16] Thakur, D., Roberts, B., Rieke, R.D., and White, T., 1999. Fatty Methyl Ester Hydrogenation to Fatty Alcohol : Reaction inhibition by
Glycerine \& Monoglyceride,

American Oil Chemists'

Society, 76(8) : 995-1000 